\title{
Admission test as a screening test for fetal distress in labour
}

\author{
Smitha B. Rao, Reena D'Souza*, Bhavana Sherigar, Soumya R., \\ Vismaya Kaveri, Anamika Singh
}

Department of Obstetrics and Gynecology, Yenepoya Medical College, Manglore, Karnataka, India

Received: 22 January 2018

Accepted: 13 February 2018

\section{*Correspondence:}

Dr. Reena D'Souza,

E-mail: smitharao_007@gmail.com

Copyright: (c) the author(s), publisher and licensee Medip Academy. This is an open-access article distributed under the terms of the Creative Commons Attribution Non-Commercial License, which permits unrestricted non-commercial use, distribution, and reproduction in any medium, provided the original work is properly cited.

\section{ABSTRACT}

Background: This study was undertaken with the purpose of evaluating the efficacy of labour admission test as a screening test to identify the compromised fetus or fetus at risk and to correlate with perinatal outcome.

Methods: This was a retrospective cohort study of 300 patients in 1st stage of labour admitted to labour room at tertiary care hospital over a period of one and a half years. Patients with Singleton pregnancy, Cephalic presentation \& Gestational age beyond 34 weeks were included in this study. A BPL electronic foetal heart monitor was used to perform the admission test. With the patient in left lateral position a 20 minute continuous electronic recording (paper speed of $3 \mathrm{~cm}$ per minute) of foetal heart rate and uterine activity was obtained, on a cardiotocograph.

Results: Statistical significance was calculated between different categories for different parameters too. A p value of of $<0.05$ was considered to be statistically significant. Fetal distress was seen $64.71 \%$ in Category III group $33.33 \%$ with Category II group and $4.74 \%$ in Category I trace. admission test has $97.75 \%$ specificity and $95.5 \%$ negative predictive value.

Conclusions: Admission test makes screening convenient. Since it is non-invasive, patients also cooperate. Admission test helps to plan subsequent management of labour. It is a good predictor of foetal well-being at the time of admission and for the next few hours.

Keywords: Fetal distress, Foetal hypoxia, Labour admission test

\section{INTRODUCTION}

The birth of a healthy baby is an universal aim. The potentially dangerous effects of parturition on the foetus have been intuitively recognized for centuries.

Freeman (1975) and Lee and colleagues (1975) introduced the non stress test to describe acceleration of fetal heart rate is a sign of fetal health in response to fetal movement. ${ }^{1}$ This test involved the use of Doppler detected fetal heart rate acceleration coincident with fetal movements perceived by the mother.

In this study NST was used for routine antepartum fetal surveillance to detect those fetuses that might be at risk and provide prompt intervention thus giving the best outcome in mothers and fetus. Labour interferes with the umbilical and uteroplacental blood flow and affects the foetal gas exchange, oxygenation and nutrition. ${ }^{2}$ This led to various fetal surveillance measures which may detect any fetal distress and lead to timely intervention. One such test is "labour admission test".

Ingemarsson introduced this test which comprises of a CTG trace of 20-30 minutes duration carried out on admission to the labour room. The aim of the test is to assess fetal well-being at the onset of labor and identify those fetuses that may be already hypoxic or may not withstand the stress of uterine contractions which can expose them to hypoxia in labour. ${ }^{3}$ 
Electronic monitoring of FHR is a routine practice in developed countries but has limited routine use in developing countries due to economic considerations thereby requiring selection of fetuses for continuous monitoring. ${ }^{4}$

This study was undertaken with the purpose of evaluating the efficacy of labour admission test as a screening test to identify the compromised fetus or fetus at risk and to correlate with perinatal outcome.

\section{METHODS}

This was a retrospective cohort study of 300 patients in 1ststage of labour admitted to labour room in a tertiary care hospital over a period of one and a half years. Patients with Singleton pregnancy, cephalic presentation and gestational age beyond 34 weeks were included in this study. Patients who were electively posted for caesarean section and who delivered beyond 24 hours after the admission test excluded.

Patients were first given a description of the procedure they had to undergo. No sedation was used prior to recording except in those cases that were on sedation as part of their treatment for pregnancy induced hypertension.

After a preliminary history taking, taking particular note of high risk factors such as previous perinatal loss, previous or existing intrauterine growth restriction, bleeding in pregnancy, diabetes mellitus, reduced foetal movements and a variety of other factors, a thorough general and obstetric examination was done.

A BPL electronic foetal heart monitor was used to perform the admission test. With the patient in left lateral position a 20 minute continuous electronic recording (paper speed of $3 \mathrm{~cm}$ per minute) of foetal heart rate and uterine activity was obtained, on a cardiotocograph.

The cardiotocographic traces were categorized as

- Category I: FHR tracings are normal

- Category II: FHR tracings are indeterminate

- Category III: FHR tracing are abnormal (as per American College of Obstetrics and Gynecologists (ACOG) Practice bulletin. No 106, guidelines for interpretation of CTG tracing). ${ }^{5}$

Patients with category I admission test were monitored by intermittent auscultation for $1 \mathrm{~min}$, every $30 \mathrm{~min}$ during 1 st stage of labour and every $5 \mathrm{~min}$ during 2 stage of labour. Those having category II tracing were monitored by continuous CTG monitoring or intensive auscultatory methods. Those with category III trace were taken as foetal distress and were also put for continuous fetal monitoring.
Delivery conducted was either by normal vaginal route, instrumental vaginal delivery or by caesarean section depending upon the foetal heart rate tracings and their interpretations as per the case. Colour of liquor was noted at the time of delivery. All new born babies were assessed after the delivery and at 1 and 5 minute APGAR score noted. The neonatal outcome was also recorded including the requirement of NICU admission.

The various traces obtained were compared with the neonatal status at birth using the parameters already mentioned. The outcome variables noted were:

- $\quad$ APGAR Score at $1 \min (>7$ or $<7)$

- APGAR Score at 5 min $(>9$ or $<9)$

- Color of liquor (clear, Thin or Thick meconium)

- Mode of delivery (Vaginal, Instrumental (vacuum or forceps) or LSCS)

- ICU Admission.

\section{Statistical analysis}

Data analysis and statistical verification was done by Nonparametric chi-square test using SPSS Version 15.0 statistical analysis software. Statistical significance was calculated between different categories for different parameters too. A p value of $<0.05$ was considered to be statistically significant.

\section{RESULTS}

There are total 300 patients studied from which majority had a Category I trace. i.e. $91.33 \%$ and $5.66 \%$ patients had Category III trace (Table 1).

Table 1: Outcome of admission test in 300 women.

\begin{tabular}{|lll|}
\hline Admission test & No. of women & Percentage \\
\hline Category I & 274 & 91.33 \\
\hline Category II & 9 & 3.0 \\
\hline Category III & 17 & 5.66 \\
\hline
\end{tabular}

9\% had foetal distress. $64.71 \%$ patients with Category III trace had foetal distress. $\mathrm{P}$ value $<0.001$ (Table 2).

Table 2: Incidence of foetal distress.

\begin{tabular}{|lll|}
\hline Admission test & Number & Percentage \\
\hline Category I & 13 & 4.74 \\
\hline Category II & 3 & 33.33 \\
\hline Category III & 11 & 64.71 \\
\hline Total & 27 & 9 \\
\hline
\end{tabular}

These results are comparable to various other studies (Table 3). It is can be observed from Table 1, Table 2 and Table 3 that numbers of fetal distress significantly increase with worsening of admission test $(p<0.001)$. 
Table 3: Comparison of various studies for incidence of foetal distress.

\begin{tabular}{|c|c|c|c|c|}
\hline \multirow[b]{2}{*}{ Study } & \multirow[b]{2}{*}{ No. } & \multicolumn{3}{|c|}{ Incidence of fetal distress (\%) } \\
\hline & & $\begin{array}{l}\text { Category } \\
\text { I }\end{array}$ & $\begin{array}{l}\text { Category } \\
\text { II }\end{array}$ & $\begin{array}{l}\text { Category } \\
\text { III }\end{array}$ \\
\hline Rahman et al ${ }^{4}$ & 176 & 7 & 39 & 85 \\
\hline Nagure et $\mathrm{al}^{6}$ & 160 & 11.3 & 39.1 & 85.7 \\
\hline Kansal et $\mathrm{al}^{7}$ & 500 & 16 & 62.9 & 97.3 \\
\hline Hegde at $\mathrm{al}^{8}$ & 200 & 3.6 & 15 & 75 \\
\hline Nikita at $\mathrm{al}^{9}$ & 100 & 5.2 & 40 & 66.7 \\
\hline Present study & 300 & 4.74 & 33.33 & 64.71 \\
\hline
\end{tabular}

$52.94 \%$ patients with Category III trace group had thick meconium, compared to $11.11 \%$ and $5.10 \%$ in Category II and Category I groups ( $\mathrm{p}<0.001)$.

$64.71 \%$ baby born to patients with Category III trace had NICU admission compared to $22.22 \%$ and $4.74 \%$ of those babies born to patients with Category II and Category I trace $(p<0.001)$. there was no intrapartum or neonatal deaths in babies born to mothers in Category I and Category II. In the Category III trace group 52.94\% babies had APGAR $<7 / 10$. There were $11.76 \%$ (2) neonatal deaths (Table 4).

Table 4: Relationship between admission test and fetal/neonatanal outcome.

\begin{tabular}{|c|c|c|c|c|c|c|c|c|}
\hline \multirow{2}{*}{ Admission test } & \multicolumn{2}{|c|}{ Thick meconium } & \multicolumn{2}{|c|}{ APGAR Score at min $<7 / 10$} & \multicolumn{2}{|c|}{ NICU admission } & \multicolumn{2}{|c|}{ Neonatal deaths } \\
\hline & No. & $\%$ & No. & $\%$ & No & $\%$ & No & $\%$ \\
\hline Category I & 14 & 5.10 & 6 & 2.18 & 13 & 4.74 & 0 & 0 \\
\hline Category II & 1 & 11.11 & 2 & 22.22 & 2 & 22.22 & 0 & 0 \\
\hline Category III & 9 & 52.94 & 9 & 52.94 & 11 & 64.71 & 2 & 11.76 \\
\hline
\end{tabular}

In Category I trace most of the subjects $85.03 \%$ had full term vaginal delivery and remaining $11.67 \%$ had caesarean delivery, and $3.28 \%$ had instrumental delivery.

In Category II, $44.44 \%$ subjects had caesarean delivery followed by those having full term vaginal delivery $55.55 \%$. Among Category III trace subjects maximum had LSCS delivery $70.58 \%$ followed by instrumental delivery $5.88 \%, 23.52 \%$ subjects had full term vaginal delivery (Table 5).
Table 5: Mode of delivery in 300 women.

\begin{tabular}{|lll|lll|l|}
\hline $\begin{array}{l}\text { Admission } \\
\text { test }\end{array}$ & $\begin{array}{l}\text { Normal } \\
\text { vaginal } \\
\text { delivery }\end{array}$ & \multicolumn{2}{l|}{$\begin{array}{l}\text { Instrumental } \\
\text { delivery }\end{array}$} & \multicolumn{2}{l|}{ Lscs } \\
\hline Category I & 233 & 85.03 & 9 & 3.28 & 32 & 11.67 \\
\hline Category II & 5 & 55.55 & 0 & 0 & 4 & 44.44 \\
\hline Category III & 4 & 23.52 & 1 & 5.88 & 12 & 70.58 \\
\hline
\end{tabular}

Table 6: Indication for LSCS and instrumental delivery.

\begin{tabular}{|c|c|c|c|c|c|c|c|c|}
\hline \multirow{3}{*}{ Admission Test } & \multicolumn{4}{|c|}{ LSCS } & \multicolumn{4}{|c|}{ Instrumental delivery } \\
\hline & \multicolumn{2}{|c|}{ Foetal distress } & \multicolumn{2}{|c|}{ Other indication } & \multicolumn{2}{|c|}{ Foetal distress } & \multicolumn{2}{|c|}{ Other indications } \\
\hline & No. & $\%$ & No. & $\%$ & No. & $\%$ & No. & $\%$ \\
\hline Category I & 8 & 2.91 & 24 & 8.75 & 4 & 1.45 & 5 & 1.82 \\
\hline Category II & 2 & 22.2 & 2 & 22.2 & 0 & 0 & 0 & 0 \\
\hline Category III & 10 & 58.82 & 2 & 11.76 & 1 & 5.88 & 0 & 0 \\
\hline
\end{tabular}

In patients with Category I trace $2.91 \%$ patients underwent LSCS for foetal distress. $1.45 \%$ patients had instrumental delivery for foetal distress.

In patients with Category III trace, $58.82 \%$ patients had LSCS for foetal distress and $5.88 \%$ patients had instrumental delivery for foetal distress. 24 patients with Category I trace and 2 patients with Category III trace had LSCS for other indications (Table 6).
Table 7: Interval between admission test and foetal distress.

\begin{tabular}{|l|lll|}
\hline Admission test & $\begin{array}{l}\text { Time in hours } \\
\text { Up to 3 } \\
\text { hours }\end{array}$ & $\begin{array}{l}\text { 3-6 } \\
\text { hours }\end{array}$ & $\begin{array}{l}\text { More than } \\
\text { 6 hours }\end{array}$ \\
\hline Category I (n-274) & 0 & 6 & 7 \\
\hline Category II (n-9) & 0 & 0 & 3 \\
\hline Category III (n-17) & 9 & 2 & 0 \\
\hline
\end{tabular}


Interval between admission test and detection of foetal distress in Category I and Category II trace groups was 69 hours and maximum patients in Category III trace group foetal distress was detected within 3 hours (Table 7).

\section{DISCUSSION}

In spite of labour and delivery regarded as a normal physiological process, the intrapartum complications can arise very quickly and unexpectedly in both high and low risk pregnancy. ${ }^{5}$

Table 8: Sensitivity and specificity.

\begin{tabular}{|c|c|c|c|c|}
\hline Parameters & Present study & Rahman et al ${ }^{4}$ & Ingemarsson et $\mathrm{al}^{3}$ & Nikita et al ${ }^{6}$ \\
\hline Sensitivity & $4.83 \%$ & $63 \%$ & $23.5 \%$ & $73.6 \%$ \\
\hline Specificity & $97.75 \%$ & $91 \%$ & $99.4 \%$ & $94 \%$ \\
\hline Positive predictive value & $64.70 \%$ & $55 \%$ & $40 \%$ & $60.8 \%$ \\
\hline Negative predictive value & $95.25 \%$ & $93 \%$ & $98.7 \%$ & $97 \%$ \\
\hline
\end{tabular}

Labour admission test can be used as a screening tool in early labour to identify unsuspected cases of fetal jeopardy that may benefit with continuous electronic fetal heart monitoring during labour. ${ }^{10}$

Our study population included 300 patients with both low risk and high risk factors who were admitted in labour after 34 weeks gestation, who delivered within 24 hours. 192 patients were primiparas and 108 were multiparas

In our study, most of the subjects $85.03 \%$ with Category I trace had full term vaginal delivery, $11.67 \%$ had caesarean delivery. and those who had instrumental delivery were $3.28 \%$. In Category II trace group, $44.44 \%$ subjects had caesarean delivery, full term vaginal delivery $55.55 \%$ and those having instrumental delivery $21.3 \%$. Among Category III trace subjects $70.58 \%$ had LSCS followed instrumented delivery $5.88 \%$ and $23.52 \%$ had full term vaginal delivery. These results are in concordance with studies by Gurung G, Hegde A, Kulkarni AA and Bhat RA. ${ }^{9,11-13}$

Our study showed fetal distress in $4.74 \%$ babies from Category I trace group, $33.3 \%$ from Category II group and $64.71 \%$ from Category III trace group (Table2). These observations were similar to the studies done by Rahmanet al, nikita et al, Nagure et al, Kansal et al and Hegde et al studies as shown in Table 3.4,6-9 Our study confirms that labour admission test showing Category III trace has higher risk of intrapartum foetal distress when compared to those patients Category I and II trace.

Risk factors in antepartum period are not accurate as predictors of fetal outcome as foetal heart rate changes and fetal acidosis might occur with same frequency in high and low risk groups. ${ }^{14}$ In present study, 300 pregnant women were admitted in labour with $43 \%$ of the cases in high risk group and $57 \%$ in low risk group.

The high risk factors were gestational hypertension (GHTN), premature rupture of membrane (PROM), severe anaemia, diabetes mellitus, overt diabetes, intrauterine growth restriction (IUGR), intrapartum bleeding. The results can be compared with the findings of Dwarakanath et al study (40.5\% in high risk and 59.5\% in low risk group) and Buckshee $\mathrm{K}$ et al study, (32\% in high risk and $68 \%$ in low risk). ${ }^{14,15}$

Meconium passage is considered as a sign of fOetal distress occurring due to fetal hypoxia and is considered a marker of adverse perinatal outcome. However, neonatal morbidity and mortality is primarily the result of thick tenacious meconium rather than thin meconium. In our study, the incidence of to thick meconium stained liquor was significantly high in Category III trace group $(52.94 \%)$ as compared to Category II trace $(11.11 \%)$ and Category I trace group $(5.10 \%)$.

Incidence of admission of newborn to NICU was highest in Category III trace group $(64.71 \%)$ compared to Category II $(22.22 \%)$ and Category I trace group $(4.74 \%)$. This is in agreement with studies by Rahman et al, Nagure et al.,6

LSCS for foetal distress was required only in $2.91 \%$ patients in Category I trace group, $22.22 \%$ in the Category II trace group and $58.82 \%$ in the Category III trace group. Results are comparable to $50 \%$ in Buckshee et al study, and in Nikita et al study LSCS done in $66.7 \%$ for LSCS for foetal distress. ${ }^{9,15}$

The interval between labour admission test and development of fetal distress in our study was 3-9 hours in Category I and Category II trace group and 0-6 hours in Category III trace group. Shakira et al have shown this interval to be 6 hours in reactive group, while Ingemarsson et al and Kulkarni et al showed this interval to be 6 hours and 5 hours respectively. ${ }^{3,12,16}$ Kushtagi et al have shown this interval to be 6 hours after reactive labour admission test in low risk and 3 hours in high risk mothers. ${ }^{17}$ 
So, it can be concluded that labour admission test has some prognostic value for the first few hours of admission to detect foetal hypoxia. It cannot be expected to predict fetal distress after several hours of labour with other influential factors like prolonged labour, cord problems, intrapartum bleeding which may become functional as the labour progresses.

It is recommended that where admission to delivery interval is more than 6-8 hours, intrapartum CTG should be repeated to detect foetal distress.

\section{CONCLUSION}

Admission test is a screening test, not a diagnostic tool. The advantages are its simplicity and ease of performance. The short test time makes screening convenient. Since it is non invasive, patients also cooperate. Admission test helps to plan subsequent management of labour. It is a good predictor of foetal well being at the time of admission and for the next few hours. It can detect foetal distress already present at admission and unnecessary delay in intervention is avoided. The labour admission test cannot predict the development of any acute asphyxia insult during the labour. The high specificity of the test helps to screen hypoxic foetuses in a busy labour ward and thus decreases foetal morbidity and mortality.

Funding: No funding sources

Conflict of interest: None declared

Ethical approval: The study was approved by the Institutional Ethics Committee

\section{REFERENCES}

1. Cunningham F, Leveno $\mathrm{K}$, Bloom S, Spong CY, Dashe J. Williams Obstetrics, 24e. Mcgraw-hill; 2014.

2. Nelson MD, Leviton A. How much of neonatal encephalopathy is due to birth asphyxia? Am J Dis Child. 1991;145(11):1325-31.

3. Ingemarsson I, Arulkumaran S, Ingemarsson E, Tambyraja RL, Ratnam SS. Admission test: Ascreening test for fetal distress in labor. Obstet Gynecol. 1986;68(6):800-6.

4. Rahman H, Renjhen P, Dutta S, Kar S. Admission cardiotocography; its role in predicting fetal outcome in high risk obstetric patients. Australas Med J. 2012;5(10);522-7.
5. American College of Obstetricians and Gynaecologists. ACOG Practice Bulletin No. 106: Intrapartum fetal heart rate monitoring: nomenclature, interpretation, and general management principles. Obstet Gynecol. 2009 Jul;114(1):192-202.

6. Nagure A, Umashankar M, Dharmavijay $\mathrm{N}$, Mahedarakshan S. Admission cardiotocography: Its role in predicting foetal outcome in high-risk obstetric patient. Indian $\mathrm{J}$ Basic Med Res. 2013;3(1):156-164.

7. Kansal R, Panjeta P, Mahendra R, Bansal I, Goel G, Agrawal N. To study the association between labour admission test and mode of delivery. Int $\mathbf{J}$ Pharm Med Res. 2014;2(4):109-112.

8. Hegde A, Kore S, Srikrishna S, Ambiye VR, Vaidya PR. Admission test: Screening for prediction of fetal outcome in labour. $\mathbf{J}$ Obstet Gynecol India. 2001;51(2):35-8.

9. Nikita V, Kumare B. Labour Admission Test (LAT) as a predictor of intrapartum fetal distress. Panacea $\mathbf{J}$ Med Sci. 2016;6(1):26-30.

10. Talaulikar VS, Arulkumaran S. Labour admission test. Intl J Infer Fetal Med. 2011;2(3):89-95.

11. Gurung G, Rana A, Giri K. Detection of intrapartum fetal hypoxia using admission test (AT). N J Obstet Gynaecol. 2006;1(2):10-3.

12. Kulkarni AA, Shroti AN. Admission Test: A predictive test for distress in high risk labor. J Obstet Gynecol Res. 1998;24(4):255-9.

13. Bhat RA. Labour admission test: A screening tool. Obstet Gynaecol Today. 2006;9(6):328-31.

14. Dwarakanath L, Laxmikantha G, Chaitra SK. Efficacy of admission cardiography (Admission test) to predict obstetric outcome. J Evol Med Dental Sci. 2013;2(5):418-23.

15. Buckshee K, Deka D, Padmaja V. Admission test as predictor of fetal outcome. J Obstet Gynecol India. 1999;49(2);36-7.

16. Shakira P, Haleema H. Effectiveness of admission test. J Dow Univ Health Sci. 2007;1(1):20-5.

17. Kushtagi $P$, Naragonis S. Labour admission test: An effective risk screening tool. J Indian Med Assoc. 2002;100:234-6.

Cite this article as: Rao SB, D'Souza R, Sherigar B, Soumya R, Kaveri V, Singh A. Admission test as a screening test for fetal distress in labour. Int J Reprod Contracept Obstet Gynecol 2018;7:870-4. 